\title{
8
}


\section{Avaliação do dano corporal pós-traumático por acidentes de viação e de trabalho em Angola}

Autor(es): $\quad$ Sózinho, Guido; Coelho, Luís; Magalhães, Teresa

Publicado por: Imprensa da Universidade de Coimbra

URL persistente:

URI:http://hdl.handle.net/10316.2/33235

DOI:

DOI:http://dx.doi.org/10.14195/1647-8630_22_6

Accessed : $\quad$ 26-Apr-2023 10:14:21

A navegação consulta e descarregamento dos títulos inseridos nas Bibliotecas Digitais UC Digitalis, UC Pombalina e UC Impactum, pressupõem a aceitação plena e sem reservas dos Termos e Condições de Uso destas Bibliotecas Digitais, disponíveis em https://digitalis.uc.pt/pt-pt/termos.

Conforme exposto nos referidos Termos e Condições de Uso, o descarregamento de títulos de acesso restrito requer uma licença válida de autorização devendo o utilizador aceder ao(s) documento(s) a partir de um endereço de IP da instituição detentora da supramencionada licença.

Ao utilizador é apenas permitido o descarregamento para uso pessoal, pelo que o emprego do(s) título(s) descarregado(s) para outro fim, designadamente comercial, carece de autorização do respetivo autor ou editor da obra.

Na medida em que todas as obras da UC Digitalis se encontram protegidas pelo Código do Direito de Autor e Direitos Conexos e demais legislação aplicável, toda a cópia, parcial ou total, deste documento, nos casos em que é legalmente admitida, deverá conter ou fazer-se acompanhar por este aviso.

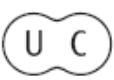




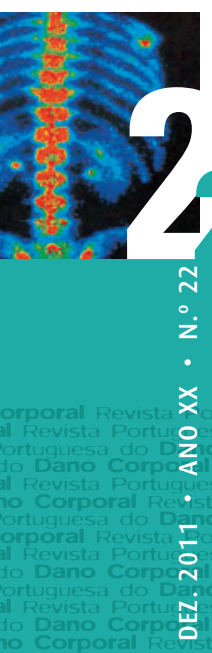

$$
\text { REVISTA PORT U/GUESA }
$$

do
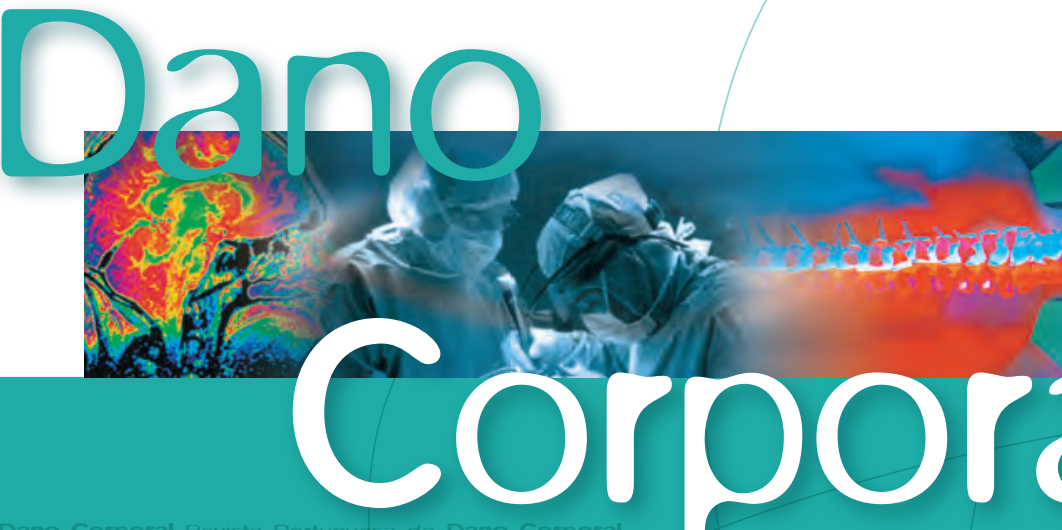

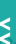

Oesa do Dano Corporal Revista Portuguesa do Dano Corporal

Zo Corporal Revista Portuguesa do Dano Corporal Revista Portuguesa do Dano Corporal

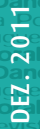

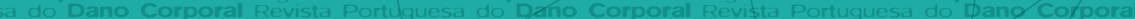

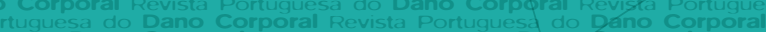

Revista Portuguesa do Dano Corporal Revista Rortuguesa do Dano Corporal
Ro Corporal Revista Portuguesa do Dano Corpgral Revista Portuguesa do Dano Corporal

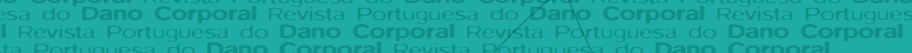




\title{
Avaliação do dano corporal pós-traumático por acidentes de viação e de trabalho em Angola
}

\author{
Guido Sózinho(1,2), Luís Coelho(3,4), Teresa Magalhães ${ }^{(3,4,5,6)}$
}

\section{INTRODUÇÃO}

\section{A sinistralidade rodoviária e laboral}

De acordo com a Organização Mundial de Saúde (OMS), em 2008 a sinistralidade rodoviária foi considerada como uma das principais causas de morte nos jovens entre os 10 e os 24 anos de idade na população mundial (4). Diariamente, morrem cerca de 3200 pessoas por acidentes rodoviários, o que perfaz um total de 1.2 milhões de vítimas por ano ${ }^{(4)}$. Estes números são especialmente graves nos países subdesenvolvidos, os quais apresentam grandes carências, não só ao nível das redes de transporte, como também ao nível de apoio hospitalar e socorro às vítimas.

Estima-se que um país perde anualmente cerca de 1 a $3 \%$ do seu produto interno bruto (PIB) com os acidentes rodoviários e suas consequências, quer ao nível da perda de capacidade produtiva, quer ao nível dos danos materiais. Este custo tem particular expressão nos países subdesenvolvidos, uma vez que nesses países esse valor equivale quase ao dobro dos fundos que lhes são atribuídos para o desenvolvimento da sua economia ${ }^{(4)}$. Perante estes factos, e

\footnotetext{
1 Departamento Nacional de Medicina Legal da Direcção Nacional de Investigação Criminal de Angola

2 Comando Geral da Polícia Nacional do Ministério do Interior da República de Angola

Instituto Nacional de Medicina Legal, I.P.

4 CENCIFOR - Centro de Ciências Forenses, Portugal

5 Faculdade de Medicina da Universidade do Porto

6 Instituto de Ciências Biomédicas “Abel Salazar” da Universidade do Porto
} 
apesar do elevado investimento dedicado à prevenção dos acidentes de viação em todo mundo, verifica-se que há ainda um longo caminho a percorrer para a redução do número de vítimas destes acidentes ${ }^{(4)}$.

Em Angola, os níveis de sinistralidade rodoviária no período compreendido entre 1 de janeiro a 24 de dezembro de 2009, registaram 12.478 acidentes, de que resultaram em 2.539 mortos e 11.396 feridos ${ }^{(2)}$. Excesso de velocidade, condução sob o efeito de álcool, desconhecimento do Código da Estrada e condução ilegal, figuram como as principais causas da sinistralidade rodoviária em todo o país ${ }^{(2)}$.

Este número de acidentes de viação, que se tem revelado crescente, constitui uma das principais causas de politraumatismos, o que justifica a existência de centros de traumatologia com equipas especializadas, conseguindo-se desta forma, em alguns países, diminuir a sua mortalidade. A avaliação inicial e ressuscitação representam um desafio mesmo para profissionais experientes, e o risco de haver lesões não diagnosticadas permanece alto, sobretudo em doentes que frequentemente estão etilizados ou apresentam alterações do estado de consciência por lesões crânio-encefálicas ${ }^{(16)}$.

Relativamente à sinistralidade no trabalho, segundo a Organização Internacional do Trabalho (OIT), todos os anos morrem no mundo mais de 1.1 milhão de pessoas, vítimas de acidentes ou de doenças relacionadas com o trabalho ${ }^{(20)}$.

Em Angola, dados da Inspeção Geral do Trabalho, do Ministério da Administração Pública Emprego e Segurança Social, em 2008, referem 285 casos de acidente de trabalho, dos quais 95 com lesões leves e 177 graves, sendo 13 fatais; traduziram-se em 84.642 dias perdidos e em indemnizações na ordem dos 364.406 kuanzas (2.250 euros) ${ }^{(2) .}$ Em 2009, registaram-se 892 casos, sendo que 309 ocorreram no setor de construção civil, 246 no setor da indústria, 145 nos transportes, 70 nas minas e um número mínimo nas restantes profissões; a indemnização foi da ordem de 140.209 kuanzas (850 euros $)^{(2)}$. Estes números estão muito subvalorizados pois, num país com mais de 14 milhões de habitantes e com um tão grande risco de sinistros, compreende-se que estes serão, necessariamente, muito superiores. $\mathrm{O}$ que acontece, é que a maior parte deles não são participados, por se assumir que a responsabilidade é da vítima, a qual não tem, geralmente, seguro para o efeito.

Certo é que a tendência dos acidentes de trabalho em Angola é para aumentar, pelo que é necessário tomar as medidas úteis que sejam adaptadas às condições da organização das empresas ou centros de trabalho, para que este seja realizado em ambiente e condições que permitam o normal desenvolvimento físico, mental e social dos trabalhadores, e que os protejam contra os acidentes de trabalho. A realização sistemática de ações de vigilância, nos ambientes e processos de trabalho, compreende o levantamento e análise de informação, a inspeção sanitária nos locais de trabalho, a identificação e 
avaliação das situações de risco, a elaboração de relatórios, a aplicação de procedimentos administrativos e a investigação epidemiológica. Compreende, ainda, a instituição e a manutenção de cadastro atualizado das empresas classificadas nas atividades económicas, com a indicação dos fatores de risco para o contingente populacional, direta ou indiretamente a eles expostos ${ }^{(19)}$.

Todas estas formas de sinistralidade constituem também matéria médico-legal, dado que implicam, deste ponto de vista, um prejuízo físico e/ou psíquico, bem como uma responsabilidade que pode ser civil, laboral e/ou penal. Assim, estes acidentes são motivo cada vez mais frequente de perícias médicas do foro penal, civil e/ou laboral. Importa, por isso, estudar esta problemática na perspetiva da avaliação médico-legal do dano corporal pós-traumático, no sentido de melhor compreender e acompanhar a sua evolução, para que os exames possam ser feitos de forma consentânea com a realidade, podendo, de alguma maneira, contribuir também para a prevenção deste tipo de sinistralidade ${ }^{(10)}$.

\section{0 regime jurídico dos acidentes de viação e de trabalho de Angola}

Aborda-se, seguidamente, de forma muito sumária, a questão do regime jurídico dos acidentes de viação e de trabalho em Angola, de modo a servir de pano de fundo para a compreensão sobre a metodologia de avaliação médico-legal dos danos corporais resultantes destes acidentes, a qual se investiga neste trabalho.

O regime jurídico dos acidentes de viação é regulado pelo Decreto-Lei 5/2008, de 15 de agosto, do Conselho de Ministros, no qual também se enquadra o Código da Estrada. A aprovação do referido Código, ferramenta essencial de uma política de segurança rodoviária, visa fundamentalmente a atualização das regras jurídicas aplicáveis ao trânsito nas vias públicas, bem como a respetiva adequação e harmonização com as melhores normas internacionais, em particular o protocolo da Comunidade de Desenvolvimento da África Austral (SADC).

As alterações introduzidas situam-se num contexto de preocupação quanto à necessária redução da sinistralidade e, simultaneamente, de maior proteção jurídica dos utentes das vias públicas, tendo por objetivo a adaptação global do sistema vigente às necessidades atuais, numa procura de equilíbrio entre as crescentes exigências colocadas pelo aumento contínuo do trânsito e a necessidade de salvaguarda da segurança de pessoas e bens.

Umas das causas de aumento de sinistralidade rodoviária em Angola é a condução de veículos sob a influência de álcool ou de substâncias legalmente consideradas como estupefacientes. Neste sentido, o regime jurídico, através do Código da Estrada, estipula artigo $80^{\circ}$ da secção XII, que é proibido conduzir sob influência de álcool ou de substâncias legalmente consideradas como 
entorpecentes. Considera-se sob influência de álcool o condutor que apresenta uma taxa de álcool no sangue (TAS), superior a 0,6 g/L ou que, após exame realizado nos termos previstos no naquele Código e legislação complementar, seja como tal considerado em relatório médico.

Também é apontado como umas das causas da sinistralidade rodoviária, a condução de veículos de duas ou quatro rodas sem habilitação para tal. No artigo $119^{\circ}$ daquele Código, diz-se o seguinte: Só pode conduzir um veículo a motor na via pública quem estiver legalmente habilitado para o efeito. A condução de veículos a motor também é permitida a instruendos e examinandos que obrigatoriamente devem estar inscritos numa escola de condução, nos termos da legislação aplicável.

Outra causa de sinistralidade, para além da condição das estradas, é a condição do veículo. Nesse sentido, o Estado proibiu a entrada no pais de veículos com mais de 5 anos após a sua fabricação.

Por outro lado, o comportamento dos automobilistas justifica muitas vezes o aumento da mortalidade dos sinistrados, dado que após o acidente abandonam as vítimas no local, seja por medo de serem vítimas de agressão, como é habitual em Luanda, seja por falta de conhecimento do Código da Estrada ou, ainda, por falta de valores como humanidade e solidariedade. Assim, no Decreto-Lei 5/2008, considera-se que o condutor que seja interveniente num acidente deve fornecer aos restantes intervenientes a sua identificação, a do proprietário do veículo e da seguradora, bem como o número da apólice, exibindo, quando solicitado, os documentos comprovativos. Se do acidente resultarem mortos ou feridos, e de acordo com o mesmo diploma, o condutor deve aguardar no local a chegada de agente de autoridade, devendo ainda providenciar do modo mais diligente possível o socorro das vítimas.

Existe um seguro automóvel, obrigatório desde 2010, tendo como objetivo a transferência dos riscos ligados ao automóvel, para a seguradora. Este seguro deverá cobrir danos próprios (danos sofridos pelo veículo), danos nos ocupantes e condutor (risco de morte, invalidez permanente, invalidez parcial e despesas de tratamento das pessoas seguradas, quando resultantes do acidente). No entanto, dado o valor do seguro, e provavelmente o facto da sua obrigatoriedade ser ainda recente, a maior parte das pessoas ainda não o tem; nestes casos, os processos têm em geral resolução judicial e o responsável, na falta de seguro, é condenado à indemnização do lesado através dos seus próprios meios ou, nessa impossibilidade, pode ter de cumprir uma pena, que pode ser de prisão - o Estado, nestas situações, apenas assegura o tratamento dos lesados, não conferindo qualquer indemnização.

Existem várias empresas seguradoras, nomeadamente a Empresa Nacional de Seguros de Angola, a Angola Agora e Amanhã, a Nossa Seguros, a Global Seguros, a Mundial Seguros, a Angola Seguros e a Garantia Seguros, onde 
também se procede á avaliação de muitos dos casos em que resulta dano corporal.

No caso da Empresa Nacional de Seguros de Angola (ENSA), por exemplo, a primeira e maior seguradora de Angola, esta garante as seguintes indemnizações e coberturas: (a) Indemnização em caso de invalidez permanente parcial/absoluta; (b) Indemnização em caso de incapacidade temporária parcial/absoluta; (c) Cobertura dos custos de tratamento e hospitalização; (d) Indemnização em caso de morte; (e) Cobertura dos custos de transporte e alojamento. A ENSA garante, ainda, a reparação de danos em consequências do acidente sofrido como: (a) Danos ou prejuízos causados a terceiros, no caso da responsabilidade civil; (b) Danos próprios sofridos pelo veículo segurado; (c) Danos dos ocupantes.

O regime jurídico dos acidentes de trabalho e doenças profissionais é regulado pelo Decreto-Lei 53/2005, de 15 de agosto. Nele é garantido o direito à reparação de danos resultantes de acidentes de trabalho e de doenças profissionais aos trabalhadores por conta de outrem e seus profissionais, protegidos pelo sistema de proteção social obrigatório. Têm ainda direito àquela reparação: (a) os trabalhadores angolanos que se encontram temporariamente no estrangeiro ao serviço do Estado, de empresas angolanas ou instituições, salvo se a legislação do país em que se encontram, lhes garantir o mesmo ou melhor direito, nos termos de convenções estabelecidas; (b) os trabalhadores estrangeiros que exerçam atividades na República de Angola, sem prejuízo de regimes especiais previstos na lei e em convenções internacionais aplicáveis; (c) os trabalhadores por conta própria, que são protegidos nos termos definidos em regulamento próprio. Assim sendo, no artigo $3^{\circ}$ do seu capítulo II, sobre os acidentes de trabalho, refere-se o seguinte naquele Decreto-Lei: Entende-se por acidente de trabalho o acontecimento súbito que ocorre no exercício da actividade laboral ao serviço da empresa ou instituição que provoque ao trabalhador lesão ou danos corporais, de que resulte incapacidade parcial ou total, temporária ou permanente para o trabalho, ou ainda a morte. São ainda considerados acidentes de trabalho os que ocorrem nas circunstâncias seguintes: (a) Durante o trajecto normal ou habitual de ida ou regresso do local de trabalho, qualquer que seja o meio de transporte utilizado no percurso; (b) Durante os intervalos para descanso, ocorridos no local de trabalho; (c) Em actos de defesa da vida humana e da propriedade social nas instalações da empresa ou instituição; (d) Durante a realização de actividades sociais, culturais e desportivas organizadas pela empresa. Considera-se trajecto normal o percurso que o trabalhador tenha de utilizar necessariamente entre a sua residência e o local de trabalho e vice-versa, dentro dos horários declarados.

Sobre a segurança dos trabalhadores o referido regime jurídico refere a obrigatoriedade dos seguros e dos encargos (artigo $7^{\circ}$ do Capítulo IV): São 
obrigatoriamente segurados contra os riscos resultantes de acidentes de trabalho e de doenças profissionais, caracterizados no presente diploma, todos os trabathadores, aprendizes e estagiários, após a efectivação do respectivo contrato de trabalho a celebrar entre a entidade empregadora e uma empresa seguradora angolana; Os trabalhadores serão submetidos a exames médicos em função do local onde é exercida a sua actividade, cujo resultado deve ser comunicado à seguradora, no prazo de 15 dias, sob pena de ser considerado causa de exclusão para efeitos de regularização de eventuais sinistros, sem que tal facto imponha prejuizo à protecção do trabalhador no tocante ao que trata o presente diploma.

Sobre as prestações em espécie, no artigo $24^{\circ}$ do Decreto-Lei 53/5, de 15 de agosto, refere-se que os sinistrados têm direito ao seguinte: (a) A assistência médica e cirúrgica, geral ou especializada, incluindo todos os elementos de diagnóstico e de tratamento que foram necessários, bem como as visitas ao domicilio; (b) A assistência medicamentosa e farmacêutica; (c) Os cuidados de enfermagem, quer no hospital ou noutra instituição médica; (d) A hospitalização e os tratamentos termais; (e) O fornecimento de próteses e ortótese, bem como a sua renovação e reparação; (f) Os serviços de reparação e reabilitação profissional e funcional.

Existe um Instituto Nacional de Segurança Social, pertencente ao Ministério da Administração Pública, Emprego e Segurança Social, Este Instituto tem como missão a proteção social obrigatória de todos os trabalhadores, apoiando-os no caso de desemprego ou invalidez. No caso de Estado, os trabalhadores ficam aí automaticamente inscritos a partir do momento em que assinam o contrato de trabalho. No caso dos trabalhadores privados, esta inscrição é obrigatória, acontecendo, contudo, que os trabalhadores muitas vezes não são escritos pela entidade patronal.

\section{A avaliação do dano corporal em Angola}

Num primeiro momento, as vítimas de acidentes de trabalho e de viação podem ser avaliadas pelo Departamento de Medicina Legal da Direção Nacional de Investigação Criminal da Policia Nacional, no que se refere aos danos suscetíveis de serem considerados no âmbito do Direito Penal, pois estes casos envolvem, frequentemente, um crime ou um litígio entre as pessoas implicadas.

Na sequência de um sinistro que ocorra com a pessoa segurada, esta é encaminhada para clínica da rede a fim de receber assistência médica. Após a conclusão do tratamento, e em função da gravidade da lesão e das sequelas do acidente, é enviado o relatório médico e o título da alta para a seguradora responsável. Face ao relatório médico, a seguradora reencaminha o sinistrado 
para a Comissão Nacional de Avaliação das Incapacidades Laborais, tutelado pelo Ministério da Saúde e Ministério do Trabalho, Emprego e Segurança Social, onde o mesmo é avaliado, fixando-se o grau de incapacidade ou invalidez. Esta é a entidade oficial que recebe os relatórios de vários sinistrados vindos das seguradoras, hospitais ou tribunais, entre outros, a fim de se atribuir um grau de incapacidade permanente. Os sinistrados avaliados por esta Comissão são enviados novamente às respetivas entidades solicitadoras, acompanhados do relatório de incapacidades. A partir daqui, é calculada a pensão a que a pessoa possa ter direito, baseando-se em fórmulas matemáticas associadas a determinados fatores, como o salário declarado, o grau de invalidez ou outros procedimentos.

A avaliação do dano corporal apoia-se no regime jurídico dos acidentes de trabalho e doenças profissionais regulado pelo Decreto-Lei 53/2005, de 15 de agosto, do Conselho de Ministros.

De acordo com artigo $21^{\circ}$ daquele diploma (Comissão Nacional de Avaliação das Incapacidades Laborais), considera-se o seguinte.

1. A determinação das incapacidades é efectuada por uma comissão, cujo composição, competência e o modo de funcionamento são fixados em diploma próprio, denominada Comissão de Avaliação das Incapacidades Laborais.

2. A comissão referida no número anterior, salvo disposição contrária, tem a seguinte constituição:

a) Um representante do Ministério da Saúde, que presidirá;

b) Um representante do Ministério de tutela da protecção social obrigatória;

c) Um representante da empresa seguradora, nos casos de avaliação dos respectivos sinistrados;

d) Um representante das associações sindicais;

e) Um representante das associações patronais;

f) Um representante da Ordem dos Médicos, quando convidado.

No ponto 3 do artigo $20^{\circ}$ do capítulo VII, refere-se que a Comissão Nacional de Avaliação das Incapacidades Laborais é obrigada ao preenchimento de um boletim, onde conste a natureza e o grau de incapacidade, em quatro vias, sendo o original para seguradora, uma via para o sinistrado, uma terceira via para os órgãos competentes do Ministério da tutela - Instituto Nacional de Segurança Social. No entanto, verifica-se que a articulação com esta Comissão, preconizada pela lei, não funciona num grande número de casos, 
sendo frequentemente, para efeitos de indemnização, os danos avaliados pelas empresas seguradoras, sobretudo no caso das pequenas incapacidades. Estas são mais de sete, atualmente em Angola, nomeadamente a Empresa Nacional de Seguros de Angola, a Angola Agora e Amanhã, a Nossa Seguros, a Global Seguros, a Mundial Seguros, a Angola Seguros e a Garantia Seguros. As seguradoras recorrem a peritos médicos privados, das diversas especialidades, não sendo frequente as vítimas recorrem a peritos privados por elas contratados.

Nos casos em que não existe acordo entre a vítima e a seguradora, a vítima pode recorrer ao Provedor da Justiça ou ao Tribunal (muitas vezes, passando primeiro pela Direção Nacional de Investigação Criminal). Nesta sequência, é geralmente solicitada nova avaliação do dano corporal, a qual poderá ser feita pelos peritos médico-legais daquela Direção Nacional, pela Comissão Nacional de Avaliação das Incapacidades Laborais ou por médicos de diferentes especialidades, nomeados pelo Juiz.

Nesta sequência, acabam por existir múltiplas entidades que realizam este tipo de práticas, não havendo normas procedimentais quanto à avaliação do dano corporal pós-traumático, muito menos harmonizadas entre elas.

Ainda assim, e tendo em conta a determinação de um valor indemnizatório, o Estado angolano aprovou a Tabela de Índices Médicos de Incapacidade, através do Decreto 86/1981, de 16 de outubro, do Conselho de Ministros. Esta Tabela foi elaborada, por imperativo constitucional, para avaliar os sinistrados de guerra que viram diminuída a sua capacidade por motivo da sua participação na luta de libertação nacional e defesa da pátria. Está, assim, em vigor há mais de 30 anos, servindo de apoio às empresas seguradoras e a outras entidades que realizam avaliação do dano corporal pós-traumático.

No seu artigo $3^{\circ}$, a Tabela refere o seguinte: as incapacidades previstas são expressas por um índice, único ou graduado, entre o mínimo e um máximo conforme o tipo de lesão. No ponto 1 do seu artigo $4^{\circ}$ diz-se que em caso de lesões múltiplas, a Tabela apenas será aplicada às que tenham sido contraídos nas circunstâncias no $\mathrm{n}^{\circ} 1$ do artigo $1^{\circ}$ do referido diploma. No ponto 2 do artigo $4^{\circ}$, refere-se que no caso do número anterior o índice global de incapacidade será determinado pela soma dos índices que correspondem a cada uma das lesões. Para este efeito, fixar-se-á primeiro o índice correspondente à lesão principal, ao qual serão adicionados os índices correspondentes às restantes lesões por ordem decrescente, até ao valor máximo de $100 \%$.

A avaliação das incapacidades resultantes é expressa em coeficientes determinados em função da natureza e da gravidade da lesão, do estado geral da vítima, da idade, da profissão, da maior ou menor readaptação efetiva para a mesma profissão, bem como das demais circunstâncias que possam concorrer para a capacidade de trabalho e de ganho. 
As incapacidades para o trabalho, segundo o resultado do acidente ou doença profissional, classificam-se, de acordo com artigo $17^{\circ}$ do Capítulo VI do Decreto-Lei 53/2005, de 15 de agosto, em: (a) Incapacidade permanente total para toda e qualquer actividade; (b) Incapacidade permanente total para o trabalho habitual; (c) Incapacidade permanente parcial; (d) Incapacidade temporária.

O grau de incapacidade define-se da seguinte forma (artigo $18^{\circ}$ do Capítulo VI):

a) Incapacidade permanente total para toda e qualquer actividade: aquela em que o trabalhador perde completa e definitivamente a capacidade para exercer qualquer actividade laboral;

b) Incapacidade permanente total para o trabalho habitual: aquela em que o trabalhador perde completa e definitivamente a capacidade para o exercício da sua profissão, podendo vir a desenvolver outra actividade após um processo de recuperação, reabilitação e readaptação profissional;

c) Incapacidade permanente parcial: aquela em que o trabalhador sofre uma redução permanente na capacidade para o exercício da sua profissão, embora continue a poder exercê-la, noutro posto de trabalho;

d) Incapacidade temporária: aquela em que o trabalhador fica impossibilitado de exercer a sua actividade profissional, ou qualquer outra por um periodo de tempo determinado. A incapacidade temporária pode ser convertida em incapacidade permanente, de acordo com o artigo $19^{\circ}$, o qual refere que verificando-se a incapacidade temporária, por um período superior a dois anos equivalente a 730 dias, considera-se incapacidade permanente.

\section{Objetivos}

Este trabalho pretende constituir-se como uma reflexão sobre a avaliação do dano corporal pós-traumático por acidentes de viação e de trabalho em Angola, reflexão esta que poderá servir para apoiar o desenvolvimento desta matéria naquele país. O assunto é complexo e o caminho é longo, atendendo à falta de normas regulamentares quanto a estes procedimentos nos diversos âmbitos do Direito, às grandes discrepâncias metodológicas existente em Angola no que à avaliação de vítimas deste tipo de traumatismos diz respeito, bem como à falta de informação, por parte dessas mesmas vítimas, quanto aos seus direitos em termos de avaliação e indemnização dos danos sofridos. De facto, sentimos que a complexidade do assunto é de tal dimensão que esta 
análise, por si só, não será de todo bastante para resolver os diversos níveis de dificuldade que nesta matéria se colocam.

Assim mesmo, o objetivo geral do presente estudo é analisar e interpretar, do ponto de vista médico-legal e forense, e face às disposições orientadoras da avaliação do dano corporal em vítimas de acidentes de viação e de trabalho em Angola, a situação atual dessas avaliações periciais, tendo em vista promover o estabelecimento de uma metodologia de avaliação que, adequando-se ao sistema legal vigente, permita servir de instrumento para melhor harmonizar a avaliação e reparação do dano corporal naquele país. Para o efeito ter-se-á como modelo o regime de avaliação destes danos seguido em Portugal pelo Instituto Nacional de Medicina Legal, I.P. (INML). Os objetivos específicos visam a caraterização dos seguintes aspetos: (a) Vítimas de acidentes de viação e de trabalho; (b) Acidentes; (c) Lesões e sequelas resultantes; (d) Parâmetros de dano corporal avaliados e valorados tendo em vista a sua reparação.

\section{MATERIAL E MÉTODOS}

\section{Material}

A amostra do presente estudo foi constituída pelos relatórios médicos elaborados na Empresa Nacional de Seguros de Angola (ENSA), para fins de indemnização por dano corporal pós-traumático, para o que foi solicitada a devida autorização. Os critérios de inclusão foram os seguintes: (a) Relatórios médicos; (b) Elaborados nos Serviços de Saúde da ENSA; (3) Entre janeiro e dezembro de 2010; (4) Relativos a vítimas de acidente de trabalho ou de acidente de viação; (5) Independentemente do sexo ou da idade; (6) Nos quais teve lugar a valoração do dano corporal devido ao acidente; (7) Estando a situação consolidada do ponto de vista médico-legal e/ou o relatório concluído. A partir da totalidade dos relatórios médicos efetuados naquele período $(n=600)$, foram selecionados os que verificavam a totalidade dos critérios de inclusão, designadamente incluindo a valoração do dano corporal $(n=301)$.

\section{Métodos}

Foi realizado um estudo observacional, com componente analítico, que consistiu numa análise dos relatórios médicos acima referidos, elaborados no âmbito da avaliação do dano corporal pós-traumático por acidentes de viação e de trabalho, relativamente aos quais seriam atribuídas as respetivas indemnizações. 
Para tal foi utilizada uma ficha de colheita de dados, expressamente construída para o efeito, a qual reúne dados relativos às vítimas, ao tipo de acidente, às lesões e sequelas sofridas, aos parâmetros de dano corporal avaliados e aos critérios que presidiram à valoração desses danos: (a) Caraterização demográfica das vítimas; (b) Caraterização dos acidentes; (c) Caraterização das lesões e sequelas; (d) Caraterização dos parâmetros de dano atribuídos. Para efeito da descrição das lesões considerou-se apenas a mais grave em cada caso. Os parâmetros de dano considerados na ficha de colheita de dados foram os preconizados pelo INML de Portugal, realidade com a qual se pretende comparar os resultados deste estudo ${ }^{(11 ; 18)}$. Todos esses dados foram colhidos pelo autor, tendo em vista garantir o cumprimento dos critérios de avaliação e, portanto, a fiabilidade da sua colheita. Os dados foram tratados no programa Microsoft Excel 2007 e no programa estatístico IBM.SPSS Statistics versão 19. Foi efectuada uma estatística descritiva, com recurso a tabelas e gráficos.

\section{RESULTADOS}

\section{Caracterização demográfica das vítimas}

A população estudada foi constituída, na sua maioria, por indivíduos do sexo masculino $(n=239 ; 79 \%)$.

A distribuição das idades por faixas etárias foi a constante na tabela 1, correspondendo o pico mais elevado às idades compreendidas entre os $21 \mathrm{e} \mathrm{os}$ 40 anos (67\%). A média da idade foi de 30 anos (mín.=7; max.=70; SD=0.80). A população de indivíduos solteiros foi largamente a mais representativa $(n=281 ; 93.4 \%)$.

Tabela 1 - Distribuição das vítimas por idade $(\mathrm{n}=301)$

\begin{tabular}{lccc}
\hline Idade & $n$ & $\%$ \\
\hline $\mathbf{1 0}$ & $\mathbf{1 1}$ a 20 & 8 & 2.7 \\
$\mathbf{2 1}$ a 30 & 26 & 8.7 \\
$\mathbf{3 1}$ a 40 & 112 & 37.0 \\
$\mathbf{4 1}$ a 50 & 90 & 30.0 \\
$\mathbf{5 1}$ a 60 & 41 & 13.3 \\
$\mathbf{6 1}$ a 70 & 18 & 6.0 \\
$>\mathbf{7 0}$ & 6 & 2.0 \\
\hline
\end{tabular}


Apenas em 49 casos consta no relatório pericial o nível de escolaridade das vítimas, pelo que esta avaliação fica muito prejudicada. De qualquer forma, nestes, o nível médio foi o mais representativo ( $\mathrm{n}=18 ; 36.7 \%)$.

Relativamente aos antecedentes patológicos, apenas num caso constava do relatório pericial os antecedentes psiquiátricos, não havendo qualquer outra referência a este aspeto nos restantes relatórios.

Os trabalhadores dos serviços de proteção, segurança pessoal, doméstico e similares, foram os que mais acidentes tiveram $(\mathrm{n}=98 ; 32.6 \%)$, seguidos pelos trabalhadores da indústria $(\mathrm{n}=60 ; 20 \%)$, mas o tipo de atividade desenvolvida não consta em 15\% dos relatórios (Tabela 2).

Tabela 2 - Distribuição das vítimas de acordo a atividade desenvolvida (n=301)

\begin{tabular}{lcc}
\hline Atividade desenvolvida & $\mathrm{n}$ & $\%$ \\
\hline Profissões científicas, técnicas, artísticas e similares & 1 & 0.3 \\
Diretores e quadros superiores & 9 & 3.0 \\
Pessoal administrativo e similares & 17 & 5.7 \\
Trabalhadores das indústrias & 60 & 20.0 \\
Serviços de proteção, segurança pessoal, doméstico e similares & 98 & 32.6 \\
Agricultores & 3 & 1.0 \\
Pessoal de comércio e vendedores & 24 & 7.6 \\
Pessoal de empresas de transporte e similares & 21 & 7.0 \\
Estudante & 22 & 7.1 \\
Outra condição & 2 & 0.7 \\
Não consta do relatório & 44 & 15.0 \\
\hline
\end{tabular}

\section{Caracterização do acidente}

A maior parte dos casos foram relativos a acidentes de trabalho $(\mathrm{n}=197$; $65.4 \%)$, sendo os restantes devido a acidentes de viação ( $\mathrm{n}=104 ; 34.6 \%)$.

Quanto ao mecanismo do traumatismo, nos acidentes de trabalho predominou o atingimento por um objeto $(\mathrm{n}=107)$, seguido de queda no local de trabalho $(n=61)$, o que corresponde a $54.3 \%$ e $31 \%$ dos acidentes de trabalho, respetivamente (Tabela 3). Já nos acidentes de viação o mecanismo mais frequente foi a colisão entre veículos em andamento $(n=47)$, correspondendo a $45.2 \%$ do total daqueles acidentes (Tabela 3 ).

Nada consta nos relatórios sobre mais pormenores relativos ao traumatismo, designadamente sobre o uso de medidas de segurança ou, no caso dos acidentes de viação, sobre a localização da pessoa no veículo. 
Tabela 3 - Distribuição das vítimas de acordo com o tipo de acidente no global dos $\operatorname{casos}(\mathbf{n}=301)$

\begin{tabular}{lcc}
\hline Tipo de acidente & $\mathrm{n}$ & $\%$ \\
\hline Colisão de veículos com objeto fixo & 32 & 10.7 \\
Colisão entre veículos em andamento & 47 & 15.7 \\
Capotamento & 7 & 2.3 \\
Atropelamento por viatura & 38 & 12.7 \\
Queda no local de trabalho & 61 & 20.3 \\
Queimadura & 8 & 2.7 \\
Atingimento por objeto & 107 & 35.7 \\
Outro & 1 & 0.3 \\
\hline
\end{tabular}

\section{Caracterização das lesões e sequelas}

As lesões mais frequentes foram as contusões e escoriações ( $\mathrm{n}=224 ; 74.7 \%)$, seguidas das fracturas $(n=36 ; 12 \%)$. Note-se, contudo, que em 3\% dos casos não foi feita referência no relatório ao tipo de lesões resultantes (Tabela 4).

Atendendo à localização das lesões, os membros inferiores foram os mais atingidos $(n=129 ; 42.9 \%)$, seguidos pelos membros superiores $(n=86$; 28.6\%) (Gráfico 1). Considerou-se, apenas, a região apresentando a lesão mais grave mas, em 10 casos, havia atingimento de múltiplas regiões $(3.3 \%)$. Note-se que em 3\% dos casos não foi feita menção no relatório à região corporal atingida.

Em 280 relatórios (93\%) não constava qualquer referência às sequelas corporais resultantes (Gráfico 2). Nos restantes casos $(n=21)$, verificou-se, maioritariamente, sequelas dos membros inferiores $(n=11)$ e superiores $(n=4)$.

Tabela 4 - Distribuição das vítimas de acordo com o tipo de lesão mais grave (n=301)

\begin{tabular}{lll}
\hline Tipo de lesão & $n$ & $\%$ \\
\hline Fraturas & 36 & 12.0 \\
Contusões/escoriações de tecidos moles & 224 & 74.7 \\
Contusões órgãos internos & 7 & 2.3 \\
Lacerações tecidos moles & 2 & 0.7 \\
Lacerações órgãos internos & 1 & 0.3 \\
Amputações & 12 & 4.0 \\
Queimaduras & 8 & 2.7 \\
Outra & 2 & 0.7 \\
Nada consta & 9 & 3.0 \\
\hline
\end{tabular}


Gráfico 1 - Distribuição das vítimas de acordo com o segmento do corpo atingido ( $n=301)$

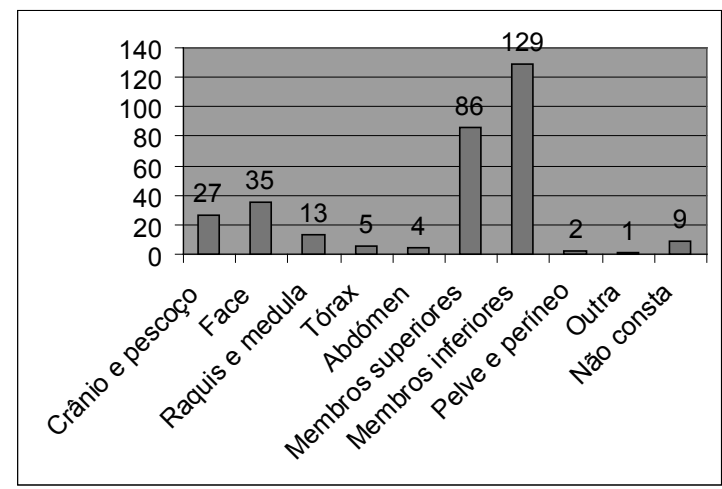

Gráfico 2 - Distribuição das vítimas de acordo com as sequelas no corpo $(\mathrm{n}=301)$

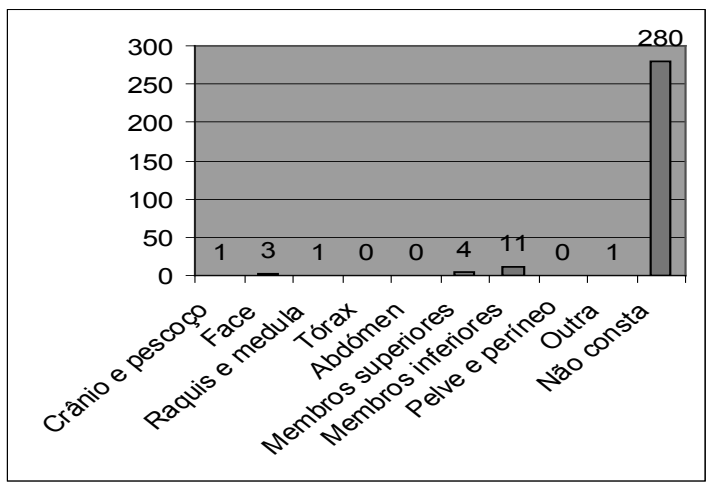

Relativamente às sequelas funcionais, apenas em 2 relatórios foi feita referência a dificuldades no deslocamento, nada constando nos restantes. Também no que às sequelas situacionais diz respeito, a estas só foi feita referência num relatório, sendo descrita afetação da vida profissional.

\section{Caracterização dos parâmetros de dano atribuídos}

Em relação ao nexo de causalidade, não é o mesmo discutido em nenhum dos relatórios. Quanto à data de consolidação das lesões, verificou-se que esta não constava em $66 \%$ dos relatórios $(n=198)$.

Relativamente aos danos temporários, e independentemente de se tratar de acidente de viação ou de trabalho, em $53.5 \%$ dos casos $(n=161)$ nada constava dos relatórios. Nos restantes $45.5 \%(\mathrm{n}=139)$ constava a atribuição da Incapa- 
cidade Temporária Geral, sendo a média de dias atribuída de 25.8 dias. Apenas num caso foi atribuída Incapacidade Temporária Profissional Parcial (0.3\%).

No âmbito dos danos permanentes, nada constava do relatório em 99\% dos casos $(\mathrm{n}=300)$. Apenas num caso foi atribuída Incapacidade Permanente Parcial; nenhum outro tipo de dano era referido nos relatórios, com exceção da referência a dependências de ajudas medicamentosas por parte da vítima em 9 casos $(3 \%)$.

\section{DISCUSSÃO}

As perícias para avaliação do dano corporal têm como objetivo final orientar a reparação integral dos danos na pessoa, quer eles sejam de natureza económica ou não económica, de forma justa e adequada às reais necessidades das vítimas ${ }^{(27)}$. Por outro lado, o objetivo principal da reparação será ajudar a vítima, de uma forma não estandardizada mas adaptada às particularidades do seu estado, de modo a repor a sua situação de vida tal como era antes do evento. Desta forma, o dano indemnizável deverá residir muito menos nas sequelas anátomo-fisiológicas do que nas múltiplas consequências no plano da vida quotidiana, da vida afetiva, familiar e da vida profissional ou de formação ${ }^{(15)}$.

Estes dois objetivos específicos devem ser orientadores do caminho a percorrer no que se refere à avaliação e reparação do dano corporal em Angola. O estudo levado a cabo permite-nos perceber que ainda se está longe de conseguir concretizar plenamente esses objetivos, mas se os peritos compreenderem que através da sua intervenção podem ajudar as vítimas a recuperar a sua situação de vida tal como ela era antes ou, pelo menos, o mais próximo disso possível, isso poderá constituir motivação bastante para se começar a operar a mudança. Para tal será logicamente necessária disciplina profissional que passará pela formação especializada nesta matéria, designadamente através da lecionação do curso de "Avaliação do Dano Corporal Pós-traumático", atualmente disponibilizado em Portugal pelo INML em conjunto com as Faculdades de Medicina das Universidades do Porto e de Coimbra. Com esse curso os peritos médicos obtêm uma ferramenta fundamental na avaliação dos sinistrados garantindo-se, desta forma, uma harmonização na utilização dos conceitos, critérios e práticas de avaliação do dano.

De seguida analisaremos os resultados obtidos neste estudo e apresentaremos, em contraponto, as metodologias que consideramos serem as mais adequadas a ultrapassar as limitações que neste âmbito da prática pericial foram detetadas. Essas metodologias estão amplamente experimentadas em Portugal e estão de acordo com as normas europeias nesta matéria. 


\section{Vítimas, acidentes, lesões e sequelas}

Os resultados, no que se refere à caracterização dos casos em análise, estão, nas suas linhas gerais, de acordo com a literatura internacional quanto às características das vítimas (indivíduos maioritariamente do sexo masculino, jovens e profissionalmente pouco diferenciados), dos mecanismos dos traumatismos para os acidentes de viação e de trabalho (colisões e atingimento por objetos ou quedas, respetivamente), bem como ao tipo de lesões e sequelas resultantes e sua localização (contusão tecidos moles e fraturas, preferencialmente nos membros) ${ }^{(5 ; 7 ; ; ; ; ; ; 10)}$.

Não nos detivemos numa análise mais detalhada destes aspetos, designadamente estabelecendo correlações entre os dois tipos de acidentes em causa (de viação e de trabalho), dado não ser este o objetivo major do nosso estudo, tratando-se aliás, de uma matéria já amplamente descrita na literatura.

Importa contudo assinalar que, estando em causa a elaboração de relatórios para avaliação do dano corporal pós-traumático, visando a posterior atribuição de uma indemnização, a questão da descrição detalhada das lesões e sequelas resultantes constitui um aspeto fundamental para perceber a globalidade do dano e, a partir daí, se determinarem os diversos parâmetros de dano suscetíveis de serem objeto de indemnização. No caso presente, apenas numa situação estavam descritos os antecedentes patológicos (aspeto de particular interesse para a definição do nexo de causalidade entre o traumatismo e o dano observado) e em 3\% dos casos não estavam descritas nem as lesões resultantes, nem a região corporal atingida; quanto às sequelas, estas apenas eram referidas em 7\% dos relatórios no que respeitava às consequências orgânicas, só se referindo a sua repercussão funcional em 2 casos e a repercussão situacional num caso. De uma forma genérica, só em $6 \%$ dos casos era feita referência às consequências do dano para a vida da vítima.

Ora, é sabido que a deficiente realização de um exame médico-legal e/ou a elaboração pouco cuidada e rigorosa do respetivo relatório pericial pode colocar em causa o valor médico-legal da perícia ${ }^{(11)}$. Por isso, e de acordo com as Recomendações Gerais para a Realização de Relatórios Periciais de Clínica Forense Relativos ao Dano Pós-Traumático do Instituto Nacional de Medicina Legal, I.P., de Portugal (13), devem os peritos, na elaboração de um relatório pericial neste âmbito, atender a que a descrição do evento traumático e de todos os eventos subsequentes com ele relacionados, com base na informação da vítima ou de quem a acompanhe, bem como a partir dos registos clínicos relativos ao acidente em causa, é fundamental e deve incluir sistematicamente: (a) Data, local, mecanismo, tipo e circunstâncias do evento traumático; (b) Lesões resultantes (descrição genérica, de acordo com a informação prestada pela vítima e descrição detalhada de acordo com 
a informação dos registos clínicos); (c) Estabelecimentos médicos onde foi assistida, complicações surgidas e tratamentos efetuados; (d) Internamento(s) e data(s) de alta(s) hospitalar(es); (e) Consulta(s) em ambulatório e respetiva(s) data(s) de alta(s); (f) Data(s) de retoma(s) da atividade profissional ou outras circunstâncias, como a mudança de atividade, desemprego ou aposentação.

Ainda de acordo com as mesmas Recomendações ${ }^{(11)}$, é fundamental descrever-se os antecedentes pessoais patológicos e/ou traumáticos que possam ser relevantes ou influenciar o resultado final do estado sequelar relativo ao caso em análise (com base na informação da vítima ou seu acompanhante e/ou em registos clínicos, indicando-se a respetiva fonte). Tal será essencial, como já acima se referenciou, para a ponderação do nexo de causalidade entre o traumatismo e o dano, nomeadamente pela circunstância de poder dar indicações quanto a eventual estado anterior da pessoa relativamente ao traumatismo ${ }^{(29)}$.

Consta ainda das referidas Recomendações que a descrição dos danos deve ser rigorosa, clara, objetiva, pormenorizada, sistematizada e compreensível, nomeadamente para não médicos. Assim, para se garantir uma descrição global e personalizada do dano, pode seguir-se o modelo da avaliação tridimensional que inclui: corpo, funções e situações ${ }^{(10)}$.

As sequelas no corpo/orgânicas, ou seja, os aspetos biológicos com as suas particularidades morfológicas, anatómicas, histológicas, fisiológicas e genéticas, devem ser descritas de forma orientada e rigorosa, com indicação de todas as características das lesões ou sequelas, incluindo ${ }^{(11)}$ : (a) Tipo (e.g., equimose, escoriação, ferida cortante, no caso das lesões; cicatriz, dismorfia, amiotrofia, dismetria, alteração da amplitude ou da estabilidade articular, desvio do eixo ou rotação do membro, perda de segmento ou órgão, alteração na força, sensibilidade, equilíbrio, no caso das sequelas); (b) Localização precisa; (c) Cor (quando for caso disso); (d) Dimensões exatas (descrevendo dimensões e graus e, no caso do exame ortopédico e neurológico, comparando com o lado contra-lateral sempre que possível). Deve ser também feita referência independente a eventuais alterações encontradas que sejam resultantes de um estado anterior ${ }^{(11)}$. O exame físico pode ser descrito de acordo com as seguintes regiões anatómicas ${ }^{(11)}$ : crânio; face; pescoço; coluna (medula incluída); tórax; abdómen (conteúdo pélvico e períneo incluídos); membro superior direito; membro superior esquerdo; membro inferior direito (pelve óssea incluída); membro inferior esquerdo (pelve óssea incluída). Sempre que possível, todas as lesões e sequelas devem ser fotografadas, de acordo com as normas da fotografia forense, e com o prévio consentimento da vítima, fazendo-se referência às fotografias no relatório pericial.

As sequelas funcionais correspondem às capacidades físicas e mentais (atuais ou potenciais) próprias do ser humano, tendo em conta a sua idade e sexo, independentemente do meio onde este se encontre; surgem na sequência 
das sequelas a nível do corpo e são influenciadas, positiva ou negativamente, por fatores pessoais (como a idade, o estado físico e psíquico anterior, a motivação e o esforço pessoal de adaptação) e do meio (como as barreiras arquitetónicas, ajudas técnicas ou ajudas humanas) ${ }^{(11)}$. Podem descrever-se relativamente aos seguintes aspetos: (a) postura, deslocações e transferências; (b) manipulação e preensão; (c) comunicação; (d) cognição e afetividade; (e) controlo de esfíncteres; (f) sexualidade e procriação.

As sequelas situacionais correspondem à confrontação (concreta ou não) entre uma pessoa e a realidade de um meio físico, social e cultural; podem ser relativas às atividades da vida diária, familiar, social, de lazer, de educação, de trabalho ou a outras, num quadro de participação social. Surgem em consequência das sequelas a nível do corpo e das funções, variando com os fatores pessoais e do meio. As situações de vida devem ser descritas quanto aos prejuízos mais relevantes, de acordo com os seguintes aspetos: (a) atos da vida corrente; (b) vida afetiva, social e familiar; (c) vida profissional ou de formação ${ }^{(11)}$.

As instruções para avaliação de cada um dos níveis referidos podem ser consultadas nas "Instruções para utilização do Inventário de Avaliação do Dano Corporal" (10).

\section{Parâmetros de dano corporal}

No que se refere ao nexo de causalidade, verificou-se que o mesmo não é referido nem discutido nos relatórios. Ora, esta avaliação constitui a pedra de toque da avaliação médico-legal, sendo que apenas nos casos em que se admite a existência de tal nexo se pode evoluir para a definição da data de consolidação e, nessa sequência, dos parâmetros de dano temporários e permanentes. Trata-se de uma avaliação que deve ser feita sistematicamente mas que obedece a uma metodologia específica e completa, pelo que se remete a questão para a bibliografia especializada na matéria ${ }^{(29)}$.

Quanto à data de consolidação das lesões, verificou-se que no caso em apreço este não foi considerado nos relatórios periciais em $66 \%$ dos casos, tendo contudo os mesmos sido, ainda assim, concluídos. A data de consolidação é a data a que se recorre quando as lesões estabilizaram, tendo contudo resultado sequelas que, do ponto de vista médico-legal, não são suscetíveis de significativa evolução. Este conceito difere do de cura por no caso da cura não resultarem sequelas. Assim, a data de consolidação é fundamental, como já referido, para separar os períodos de dano temporário de dano permanente e, desta forma, quantificar os tempos de danos temporários (que terminam na data de consolidação). Mas também a determinação desta data, que, em geral, corresponde à data de alta da última consulta ${ }^{(11)}$, se reveste 
de particularidades e complexidades, pelo que remetemos o assunto para a literatura especializada ${ }^{(23 ; 24)}$.

Relativamente à avaliação dos parâmetros de dano corporal, temporários e permanentes, quer no âmbito do Direito Civil, quer do Trabalho, verificou-se, no presente estudo, que na maioria dos casos esta avaliação foi omissa, ou seja, de uma forma genérica, em $54 \%$ dos casos não foram descritos no relatório pericial os danos temporários e em 99\% os danos permanentes.

Este facto leva-nos a questionar sobre que elementos objetivos, de índole científica, foi então determinada a indemnização devida a estes casos?

Porque se trata de uma matéria delicada e sensível, de grande complexidade, não só científica como legal, os diversos países têm-se empenhado em definir normas para este tipo de avaliações, sendo que, uma vez mais, o modelo português se nos afigura como a referência ideal, ainda mais que ele próprio se encontra alinhado com o modelo europeu e amplamente validado.

Assim, apresentaremos de seguida, ainda que de forma resumida, aquilo que, de acordo com aquele modelo, considerarmos serem os parâmetros de dano que mais se adequam a ser implementados na metodologia pericial nestes domínios em Angola.

Importa que a valoração do dano seja sempre isenta, imparcial e o mais objetiva e fundamentada possível, definindo-se os conceitos usados e identificando-se os métodos e técnicas a que se recorre. A valoração dos diversos parâmetros de dano é feita a nível do capítulo "Discussão" do relatório pericial; deste capítulo devem constar os diversos parâmetros de dano temporários e permanentes ${ }^{(18)}$.

\section{Direito Civil}

É no âmbito do Direito Civil que se analisam, em termos médico-legais, a maior parte dos danos relativos a acidentes de viação. Nesta avaliação contemplam-se danos temporários e permanentes, patrimoniais (económicos) e não patrimoniais (não económicos), dentro do princípio geral da reparação integral dos danos.

No período de danos temporários incluem-se os seguintes parâmetros que aqui se caraterizam ${ }^{(18)}$ :

a) Défice funcional temporário: corresponde ao período durante o qual a vítima, na sequência do processo evolutivo das lesões, no sentido da cura ou consolidação, viu condicionada a sua autonomia na realização das atividades da vida diária, familiar e social (excluindo-se a repercussão na atividade profissional). Poderá ser total ou parcial, coincidindo a primeira situação com os períodos de internamento e/ou de repouso absoluto, e iniciando-se a segundo logo que 
a evolução das lesões passe a permitir algum grau de autonomia na realização desses atos, ainda que com limitações. Quantifica-se em número de dias de défice funcional temporário total e de défice funcional temporário parcial, avaliados tendo em consideração a análise dos registos clínicos relativos à situação (e.g, hospitalares, médico assistente, da seguradora), o quadro clínico concreto, a informação obtida (e.g., a partir do sinistrado, familiares ou acompanhante), e as limitações naturalmente decorrentes da situação. No caso de não existirem elementos suficientes esclarecedores (muito particularmente registos clínicos), deve avaliar-se este dano com base nos períodos de tempo de défice funcional temporário total e de défice funcional temporário parcial habitualmente expetáveis para um quadro clínico semelhante ao verificado, tendo em consideração a situação clínica concreta e respetiva evolução ${ }^{(23 ; 24)}$;

b) Repercussão temporária nas atividades profissionais: corresponde ao período durante o qual a vítima viu condicionada sua autonomia na realização dos atos inerentes à sua atividade profissional habitual: pode ser total ou parcial. O tempo de repercussão temporária absoluta (total) nas atividades profissionais refere-se aos períodos de internamentos e/ou de repouso absoluto, entre outros, passando a repercussão temporária parcial nas atividades profissionais logo que a evolução das lesões permita algum grau de autonomia na realização dessas atividades, ainda que com limitações. Quantifica-se em número de dias de interrupção temporária absoluta das atividades profissionais e número de dias em que as mesmas foram concretizadas com limitações, determinando-se estes dias com base na análise dos registos clínicos relativos à situação (e.g, hospitalares, do médico assistente ou da seguradora), do quadro clínico concreto, da informação obtida (e.g., a partir do sinistrado, familiares, acompanhantes ou entidade patronal) e das limitações naturalmente decorrentes da situação clínica. No caso de não existirem elementos suficientemente esclarecedores (designadamente registos clínicos), deve avaliar-se este dano com base nos períodos de tempo habitualmente expetáveis para cada um deles no âmbito de um quadro clínico semelhante ao verificado, tendo em conta a situação clínica concreta e respetiva evolução ${ }^{(23 ; 24)}$;

c) Quantum doloris: constitui um parâmetro de dano que corresponde à valorização do sofrimento físico e psíquico vivenciado pela vítima durante o período de danos temporários (entre a data do evento e a cura ou consolidação das lesões). Descreve-se através de uma escala quantitativa de sete graus de gravidade crescente (1/7 a7/7). Como critérios de valoração deverão ser considerados, entre outros, os seguintes: (1) natureza e contexto do evento traumático, suas circunstâncias e eventos imediatos; (2) tipo e número de lesões e de tratamentos instituídos; (3) duração do(s) internamentos(s) e número de intervenções cirúrgicas; (4) complicações médicas e cirúrgicas; (5) duração e complexidade do período de reabilitação funcional. 
No período de danos permanentes incluem-se os seguintes parâmetros que aqui se caraterizam ${ }^{(18)}$ :

a) Afetação permanente da integridade físico-psiquico: trata-se de um parâmetro de dano que corresponde à afetação definitiva da integridade física e/ ou psíquica da pessoa, constitutiva de um défice funcional permanente com eventual repercussão nas atividades da vida diária, incluindo as familiares e sociais, e sendo independente das atividades profissionais. Constitui um dano que, sendo personalizado, deve ser valorado de uma forma metodologicamente igual em todos os casos, independentemente da atividade profissional, tendo em conta a globalidade das sequelas do caso concreto (corpo, funções e situações de vida) e tendo como elemento indicativo de referência a Tabela de Avaliação de Incapacidades em Direito Civil (Anexo II do Decreto Lei no 352/2007, de 23 de outubro). A tabela angolana não é específica para o Direito Civil e do Trabalho, sendo única; os coeficientes de incapacidade são expressos através de percentagens e em termos da sua organização ela é muito semelhante à tabela portuguesa publicada no Decreto 86/81, de 16 de outubro, pelo que se impõe a sua atualização;

b) Repercussão na atividade profissional: corresponde ao rebate das sequelas no exercício da atividade profissional habitual da vítima (atividade à data do evento), isto é, na sua vida laboral, devendo ser descrito e não quantificado;

c) Dano estético permanente: corresponde à repercussão das sequelas, numa perspetiva estática e dinâmica, envolvendo uma avaliação personalizada da afetação da imagem da vítima quer em relação a si própria, quer perante os outros. A sua avaliação é feita através de uma escala quantitativa de sete graus de gravidade crescente (1/7/ a $7 / 7)$;

d) Repercussão na atividade sexual: corresponde à limitação total ou parcial do nível de desempenho/gratificação de natureza sexual, resultante das sequelas físicas e/ou psíquicas, não se incluindo aqui os aspetos relacionados com a capacidade de procriação. A sua avaliação é feita numa escala com sete graus de gravidade crescente (1/7 a $7 / 7)$;

e) Repercussão nas atividades desportivas e de lazer: corresponde à impossibilidade estrita e especifica para a vítima de se dedicar a certas atividades lúdicas, de lazer e de convívio social, que exercia de forma regular e que para ela representavam um amplo e manifesto espaço de realização e gratificação pessoal. A sua avaliação é feita numa escala com sete graus de gravidade crescente (1/7 a 7/7); 
f) Dependências: as dependências (e.g., medicamentosas, de ajudas técnicas ou de terceira pessoa), podem ser temporárias ou permanentes, sendo valorizadas, mais frequentemente, e enquanto tal, as permanentes. Estas devem ser pormenorizadamente caraterizadas, sendo nos casos de handicap grave importante a colaboração de uma equipa multidisciplinar para a definição destas necessidades, tendo em vista a melhor reintegração possível da vítima a nível familiar, social e profissional ${ }^{(17)}$.

\section{Direito do Trabalho}

É no âmbito do Direito do Trabalho que se analisam, em termos médico-legais, os danos relativos a acidentes de trabalho.

Em sede de Direito do Trabalho avaliam-se danos temporários e permanentes, mas apenas patrimoniais, tendo em conta a sua repercussão a nível das capacidades de trabalho e de ganho. No período de dano temporário incluem-se os seguintes parâmetros que se aqui caraterizam ${ }^{(11)}$ :

a) Incapacidade Temporária Profissional Absoluta: corresponde o período durante o qual a vítima esteve totalmente impedida de realizar a sua atividade profissional habitual. Incluem-se neste período os tempos relativos a internamento em serviço de saúde e os de necessidade de repouso absoluto, sem prejuízo dos resultantes das especificidades da profissão em causa. Quantifica-se em número de dias de incapacidade, determinados com base na análise dos registos clínicos relativos à situação (e.g., hospitalares, do médico assistente ou da seguradora), do quadro clínico concreto, da informação obtida (e.g., a partir do sinistrado, familiares ou acompanhante) e das exigências da sua profissão habitual. No caso de não existirem elementos suficientes esclarecedoras (geralmente registos clínicos), deve avaliar-se este dano com base no período de tempo habitualmente expetável para um quadro clínico semelhante ao verificado, tendo em conta o tipo e exigências da profissão em causa ${ }^{(23 ; 24) \text {; }}$

b) Incapacidade Temporária Profissional Parcial: corresponde ao período em que a vítima passou a ter pelo menos metade da capacidade necessária para desenvolver a sua atividade profissional habitual, ainda que com limitações. Quantifica-se em número de dias e taxas de incapacidade determinados com base na análise dos registos clínicos relativos à situação (e.g., hospitalares, do médico assistente ou da seguradora), do quadro clínico concreto, da informação obtida (e.g., a partir do sinistrado, familiares ou acompanhante) e das exigências da sua profissão habitual. Também aqui, e se não existirem elementos suficientes esclarecedoras (como registos clínicos), deve avaliar-se este dano com base no período de tempo 
habitualmente expetável para um quadro clínico semelhante ao verificado, tendo em consideração a situação clínica concreta e respetiva evolução, bem como o tipo e exigências da profissão em causa.

No período de dano permanente incluem-se os seguintes parâmetros que aqui se caraterizam ${ }^{(11)}$ :

a) Incapacidade Permanente: corresponde à perda da capacidade de trabalho em resultado de uma ou mais disfunções, como sequelas(s) final(ais) da(s) lesão(ões) inicial(ais), sendo a disfunção total designada por incapacidade permanente absoluta para todo e qualquer trabalho. Podem existir diversos níveis de incapacidade permanente: incapacidade permanente parcial (IPP), incapacidade permanente absoluta para o trabalho habitual (IPATH) e incapacidade permanente absoluta para todo e qualquer trabalho (IPA). A IPP é calculada tendo em conta a globalidade das sequelas do caso concreto (corpo, funções e situações de vida, com particular valorização da atividade profissional), sendo a quantificação (em percentagem) dessas sequelas concretizada através da Tabela Nacional de Incapacidades por Acidentes de Trabalho ou Doenças Profissionais (TNI - Anexo 1 do Decreto-Lei no 352/2007, de 23 de Outubro).Como acima referido, em Angola a tabela é única e com mais de 30 anos, sendo semelhante à primeira tabela de incapacidades portuguesa;

b) Dependências: as dependências (e.g., medicamentosas, de ajudas técnicas ou de terceira pessoa), podem ser temporárias ou permanentes, sendo valorizadas, mais frequentemente, e enquanto tal, as permanentes. Tal como referido para o Direito Civil, estas devem ser pormenorizadamente caraterizadas, sendo nos casos de handicap grave importante a colaboração de uma equipa multidisciplinar para a definição destas necessidades, tendo em vista a melhor reintegração possível da vítima a nível familiar, social e profissional.

\section{Modelo de relatório pericial}

Referiu-se, também, ao longo deste trabalho, que em Angola não existe um modelo de relatório pericial de avaliação do dano corporal, o que impede a harmonização das práticas. Este modelo, está, obviamente ligado á necessária definição dos diversos parâmetros de dano que hão-de ser avaliados, pelo que os dois aspetos têm de ser ponderados em conjunto.

No caso concreto, e atendendo à realidade angolada em termos legais, relativamente á matéria em questão, parece-nos que os modelos de relatório atualmente em vigor no INML para a avaliação do dano corporal pós-traumático, cujas normas procedimentais se encontram publicadas ${ }^{(13)}$, é perfeitamente 
adaptável às necessidades deste país. O modelo inclui os seguintes capítulos, correspondentes às diferentes fases de realização da perícia: "Preâmbulo", "Informação", "Estado atual", "Discussão" e "Conclusões".

O "Preâmbulo" refere-se à identificação do processo e da vítima. Nele deve constar: tipo e data do exame; identificação do processo judiciário ou particular; identificação da vítima (nome, filiação, sexo, data de nascimento, estado civil, profissão, naturalidade, nacionalidade, residência e número do bilhete de identidade).

O capítulo da "Informação" divide-se em três sub-capítulos: História do Evento, Dados Documentais e Antecedentes:

a) Na "História do Evento", descreve-se o traumatismo e suas consequências com base na informação da vítima e/ou de quem a represente. É fundamental para perceber a vivência do trauma e fundamentar os danos a atribuir, muito particularmente os mais subjectivos. Inclui: (1) data, local, mecanismo, tipo e circunstâncias do evento traumático; (2) lesões resultantes (descrição genérica, de acordo com a informação prestada pela pessoa); (3) estabelecimentos médicos a que houve recurso, complicações surgidas e tratamentos efectuados; (4) data de alta hospitalar; consultas em ambulatório; (5) data de reinício da actividade profissional ou outras circunstâncias, como a mudança de actividade profissional, o desemprego ou a aposentação;

b) Os "Dados Documentais" são elementos fundamentais para a descrição concreta das lesões sofridas e dos tratamentos efectuados, sobretudo tratando-se de uma situação com algum tempo de evolução, na qual o perito já não observa as lesões iniciais, sendo nesse caso obrigatória a consulta desses registos documentais, geralmente clínicos. Deve ser feita uma descrição cronológica dos dados relevantes, evitando-se transcrições, mas havendo sempre que indicar a fonte da informação. Neste sub-capítulo refere-se: (1) a data do evento traumático; (2) as lesões resultantes (descrevendo as lesões de forma ordenada, de cima para baixo, da direita para a esquerda e de fora para dentro, contemplando todos os registos clínicos - se houver discrepância entre alguns deles deve referir-se esse aspecto); (3) a indicação dos estabelecimentos médicos a que houve recurso, as complicações surgidas e os tratamentos efectuados; (4) a(s) data(s) de alta hospitalar; (5) as consultas em ambulatório (especialidades, instituições, tratamentos, exames de diagnóstico complementar efectuados e período de consultas com referência às datas de alta); (6) os parâmetros de dano valorados por outros peritos, se for caso disso.

c) Os “Antecedentes", referem-se aos pessoais patológicos e/ou traumáticos que podem ser relevantes ou influenciar o resultado final do estado sequelar relativo 
ao caso em análise (com base na informação da vítima e/ou em registos clínicos), podendo descrever-se, também, os aspectos relevantes dos antecedentes patológicos familiares, caso existam. Este aspeto é fundamental para a determinação do nexo de causalidade entre o traumatismo e o dano, na medida em que nele é feita a análise do estado anterior da pessoa relativamente ao traumatismo.

O capítulo do "Estado atual" inclui as "Queixas", o "Exame objetivo" e os "Exames complementares":

a) Nas "Queixas", descrevem-se os danos relativamente às funções e situações de vida, níveis estes já atrás referidos. Dado que na maior parte dos casos são evidenciados aspectos descritos pela vítima, importa fazer uma entrevista orientada e sistematizada, mas com recurso frequente a perguntas abertas, que não sugiram as respostas.

b) No "Exame objetivo" descreve-se o dano no "Corpo". Deve começar-se pelo estado geral da pessoa, fazendo-se depois uma descrição orientada e rigorosa, com indicação de todas as características das lesões ou sequelas, também já atrás descritas. Deve ser também feita referência a eventuais alterações encontradas que sejam resultantes de um estado anterior.

c) A nível dos "Exames Complementares de Diagnóstico", descrevem-se as conclusões dos exames solicitados pelo perito, indicando-se a data e local de proveniência dos mesmos (e.g., parecer de ortopedia ou de oftalmologia, relatório de exame imagiológico ou eletrofisiológico).

O capítulo da "Discussão" será elaborado se for possível concluir definitivamente o relatório e será diferente conforme o âmbito do Direito em que a perícia esteja a ser realizada. Neste capítulo incluiu-se, em todos os casos, a discussão do nexo de causalidade e a definição da data da cura ou da data de consolidação médico-legal das lesões, aspetos também atrás já discutidos.

Depois de referir estes dois aspetos, procede-se à interpretação dos resultados do exame efetuado, o que se faz em dois momentos: período de danos temporários e período de danos permanentes. Os parâmetros do dano que se irão discutir dependerão do âmbito do Direito em que o exame tem lugar.

O capítulo das "Conclusões" pode ser preliminar ou definitivo. Se não for possível concluir o relatório de forma definitiva (por ainda não ter sido atingida a cura ou consolidação médico-legal das lesões, porque são necessários exames complementares ou de outras especialidades, ou porque são necessários registos clínicos, etc.), apresentam-se "Conclusões Preliminares", indicando-se o que se necessita para se poder concluir o exame, bem como se é ou não necessária nova presença da vítima. As "Conclusões", quando 
definitivas, não deverão ser longas, incluindo apenas a referência à existência ou inexistência de nexo de causalidade, à data de cura ou de consolidação médico-legal das lesões, e aos diversos parâmetros de dano mencionados e fundamentados na "Discussão".

\section{Perspetivas futuras}

Do perito médico é esperado que dê uma resposta adequada ao objetivo da perícia, de forma sempre imparcial e objetiva, descrevendo a complexidade do dano corporal sob o ponto de vista técnico com palavras simples, para que todos os profissionais implicados nas questões de avaliação e reparação deste dano a possam analisar sobre bases concretas, garantindo-se, assim, que a decisão sobre a indemnização a aplicar se fundamenta na informação pericial ${ }^{(1 ; 25)}$.

Para isso, o perito médico deve seguir e respeitar normas, modelos e metodologias periciais que para cada tipo de avaliação médico-legal tenham sido superiormente definidas, sendo esta a única via possível para a harmonização da atividade pericial, de forma a que se observe o princípio da equidade, ou seja, o tratamento igualitário de situações equivalentes. Essa harmonização é fundamental como garante de uma boa administração da Justiça e não coarta, de forma alguma, a liberdade técnico-científica dos peritos médicos, nem limita a plena manifestação das capacidades daqueles que, por via da sua elevada experiência, enriquecem o exercício desta atividade pericial ${ }^{(14)}$. Efetivamente, o perito deve gozar sempre de autonomia no exercício das suas funções, sendo o responsável pela elaboração do relatório pericial, o que não colide com o facto de dever estar obrigado a respeitar as normas, modelos e metodologias periciais, tal como é consignado na lei portuguesa relativa às perícias médico-legais (Lei 45/2004, de 19 de agosto). Esta autonomia é, aliás, fundamental para que o perito não se sinta constrangido na redação das conclusões que considere mais adequadas a cada caso. De facto, a pessoa que realizou o exame é a que mais aprofundadamente observou a vítima e analisou o caso, pelo que será a que se encontra em melhores condições para proceder à correta valoração dos danos; isto confere, também, uma maior responsabilidade ao seu trabalho ${ }^{(14)}$.

As normas e metodologia de realização do exame e de elaboração do relatório devem ser adequadas a cada âmbito do Direito e aos seus respetivos objetivos, pelo que, independentemente do modelo de relatório pericial, de uma forma genérica, poder ser semelhante, independentemente do âmbito do Direito em que este se esteja a elaborar, deverão existir normas adaptadas a cada âmbito do Direito em que a perícia tem lugar, designadamente Penal, Civil e Trabalho, sobretudo no que aos capítulos da Discussão e Conclusões diz 
respeito. Por isso, é fundamental existirem normas procedimentais adaptadas aos objetivos de cada ramo do Direito, as quais orientem cada tipo de perícia, sendo certo que a perícia pode ter relevantes implicações na decisão judicial.

Dos resultados deste estudo concluí-se que a avaliação do dano corporal pós-traumático em Angola, no caso dos acidentes de viação e de trabalho, tendo em vista a indemnização da vítima, apesar de ser concretizada, não obedece a qualquer tipo de norma (por esta não existir). Acresce que nos casos em que os procedimentos com vista à avaliação e reparação dos danos estão legalmente regulamentados, estes não obtêm, num grande número de casos, o seu cumprimento, seja porque se tratam de normas ainda recentes, seja porque os intervenientes as desconhecem ou não as interiorizaram ou, ainda, porque no terreno não existem condições adequadas para a sua implementação. Esta constitui, pois, matéria a merecer reflexão.

Por isso, além da definição de normas para avaliação do dano corporal, existe também a necessidade de se definir em termos legais e de uma forma clara, um sistema organizacional e respetivas competências da(s) instituição(ões) envolvida(s), bem como dos peritos médios. Existe, ainda, necessidade de repensar a formação/especialização desses peritos médicos, designadamente, e neste caso, em matéria de avaliação do dano corporal pós-traumático.

No que às normas para avaliação do dano corporal diz respeito, consideramos que as portuguesas, atrás descritas, se podem facilmente adaptar à situação legal angolana, havendo até diversas similitudes no que às questões a nível laboral se refere. Já no que aos instrumentos de avaliação se refere, designadamente a tabela de incapacidades, julgamos que importará ponderar a sua atualização, bem como o interesse de separar claramente a tabela para acidentes de viação da dos acidentes de viação.

Assinale-se, ainda, que para além da avaliação do dano corporal numa perspetiva mais física, importa que os médicos que trabalham com vítimas deste tipo de acidentes conheçam e percebam o mecanismo psicológico do trauma e as suas consequências, o que é fundamental não apenas para garantir corretos diagnósticos mas, também, a adequada abordagem da vítima, tendo em vista evitar a sua vitimação secundária (agravamento do trauma sofrido). De facto, o trauma não corresponde apenas ao traumatismo físico, sendo que os eventos traumáticos podem ter etiologias diversas e consequências orgânicas, psicológicas e/ou sócio económicas ${ }^{(26)}$. Por outro lado, um dano psicológico ou emocional pode existir independentemente do dano orgânico, o que pode ser valorado, para efeitos de dano corporal, num quarto nível a acrescentar à atrás referida avaliação tridimensional do dano, neste caso do nível da subjectividade ${ }^{(6)}$.

Por tudo isto, existe a necessidade de uma formação/especialização dos peritos médicos. Essa formação, e como já atrás referido, existe em Portugal, 
sendo de ponderar a possibilidade de importar esse modelo o que, numa primeira fase, pode passar por levar até Angola a organização do "Curso de Avaliação do Dano Corporal Pós-Traumático". Isso já começou, aliás, a ser feito com o Brasil.

Já quanto à organização dos procedimentos periciais, consideramos que o modelo de funcionamento das perícias médico-legais em Portugal, consignado na Lei 45/2004, de 19 de agosto, mereceria ser analisado e adaptado, nas suas virtualidades, à realidade angolana. Isto poderia implicar, por exemplo, que o Departamento Nacional de Medicina Legal da Direção Nacional de Investigação Criminal de Angola visse as suas competências alargadas para além da intervenção criminal, o que acarretaria pesadas mudanças em termos legais. Acreditamos, contudo, que a atividade pericial, pelas suas especificidades, resulta favorecida, sobretudo em termos de qualidade, se funcionar toda no mesmo organismo, garantidas que estejam as questões de imparcialidade e de isenção.

\section{CONCLUSÕES}

O presente estudo revelou que a avaliação do dano corporal em Angola está a dar os seus primeiros passos, não existindo ainda uma metodologia definida e harmonizada, fundamental para garantir a equidade da avaliação e, consequentemente, a justiça da reparação.

Deste estudo resulta que os relatórios periciais alvo de análise $(\mathrm{n}=301)$, e independentemente de serem elaborados por motivo de acidente de viação ou de trabalho:

a) Não descrevem os antecedentes patológicos e traumáticos das vítimas,

b) Descrevem o mecanismo do traumatismo/acidente, sem contudo o pormenorizar;

c) Em 3\% dos casos não fazem referência às lesões resultantes nem à localização dessas lesões;

d) Em 93\% dos casos não descrevem as sequelas a nível do corpo;

e) Em quase 100\% não descrevem as sequelas funcionais nem situacionais;

f) Nunca fazem referência ao nexo causalidade entre o traumatismo e o dano;

g) Em 66\% dos casos não fazem referência à data de consolidação médico-legal das lesões;

h) Em 54\% dos casos não fazem referência aos parâmetros de dano temporário;

i) Em $99 \%$ dos casos não fazem referência aos parâmetros de dano permanente. 
Note-se que estes relatórios correspondem, apenas, à realidade de uma entidade, a qual os disponibilizou para estudo, sendo certo que, por conhecermos a realidade angolana podemos afirmar que este panorama é semelhante pelo menos à maioria dos outros casos.

Revela-se, pois, necessário definir normas procedimentais para a realização dos exames e elaboração dos relatórios periciais, que permitam a harmonização destas práticas a nível do país, as quais se poderão inspirar no modelo português que aqui fomos apresentando nas suas linhas gerais.

Necessário será, também, investir na formação de pessoal de todos os médicos que exercem ou venham a exercer atividade pericial desta índole. De facto, "no que se refere à avaliação do dano corporal, é imprescindível que o perito médico, no desenvolvimento da sua missão pericial, conheça o regime jurídico que a rege e tenha a perceção do alcance e das consequências dos seus pareceres, por forma a elaborar os relatórios perícias de maneira adequada e em harmonia com a ordem jurídica" (15), dado que tal irá condicionar significativamente a possibilidade de à vítima ser proporcionada a sua adequada reabilitação e reintegração, bem como atribuída a justa reparação do dano.

Finalmente, importará repensar a organização médico-legal angolana, o que será fundamental para apoiar a implementação dos procedimentos normativos a que aqui fizemos referência.

\section{REFERÊNCIAS BIBLIOGRÁFICAS}

(1) Anciaux P, Attanian E (1993): L'expert et le préjudice non économique. Rev. Franç. Dommage Corp, 19(4):345-361.

(2) ANGOP (2010). Balanço de sinistralidade em 2010. Acedido no 10 dia de março de 2011 em portalangop.co.ao.

(3) ANSR (2009). Estratégia Nacional de Segurança Rodoviária 2008-2015 - Autoridade Nacional de Segurança Rodoviária, Lisboa.

(4) Baião F (2010). Sinistralidade Rodoviária Urbana. Caso de Estudo do Montijo. Dissertação para obtenção de grau de Mestre em Engenharia Civil: Instituto Superior Técnico da Universidade Técnica de Lisboa. Acedido no dia 12 de março de $2011 \mathrm{em}$ dspace.ist.utl.pt/bitstream/2295/792408/1/dissertacao.pdf.

(5) Carneiro MC, Pedregal DJ (2010). Modelling and forecasting occupational accidents of different severity levels in Spain. Reliability Engineering and System Safety, 95:1134-1141.

(6) Hamonet C, Magalhães T (2000). Système d'Identification et Mésure des Handicaps, ESKA, Paris.

(7) Jacinto C, Aspinwall E (2004). A survey on occupational accidents' reporting and registration systems in the European Union. Safety Science, 42:933-960.

(8) Khan ZU, Asiri Kmal, Iqbal J (2010). Injury patterns from road traffic accidents. Pak J Med Sci, 26(2): 394-397. 
(9) Macedo AC, Silva IL (2005). Analysis of occupational accidents in Portugal between 1992 and 2001. Safety Science, 43:269-286.

(10) Magalhães T (1998). Estudo tridimensional do dano corporal: lesão, função e situação. Sua aplicação médico-legal. Almedina: Coimbra pp. 471-478.

(11) Magalhães T, Antunes I, Vieira DN (2010). Recomendações gerais para a realização de relatórios periciais de clínica forense no âmbito do Direito do Trabalho. Revista Portuguesa do Dano Corporal, XIX (20): 69-78.

(12) Magalhães T, Carneiro de Sousa MJ, Matos E, e col. (1998). Análise de 108 casos de acidentes de viação não mortais. In: Vieira DN, Rebelo A, Corte-Real F, eds. Temas de Medicina Legal. Centro de Estudos de Pós-Graduação em Medicina Legal, Coimbra. pp. 381-390.

(13) Magalhães T, Corte-Real F, Costa Santos J, Vieira DN (2010). Recomendações gerais para a realização de relatórios periciais de clínica forense no âmbito do Direito Penal. Revista Portuguesa do Dano Corporal, XIX (20): 63-68.

(14) Magalhães T, Corte-Real F, Vieira D (2008). O Relatório Pericial de Avaliação do Dano Corporal em Direito Civil. In: Vieira DN e Quintero JA eds. Aspectos práticos da avaliação do dano corporal em Direito Civil. Caixa Seguros e Imprensa da Universidade de Coimbra. Coimbra. pp 95-107

(15) Magalhães T, Pinto da Costa D (2007). Avaliação do dano na pessoa em sede de Direito Civil. Perspectivas actuais, Revista da Faculdade de Direito da Universidade do Porto, IV: 419-452.

(16) Magalhães T, Taveira-Gomes A, Sousa de Carneiro MJ, Pinto da Costa J (1996). Lesões Traumáticas Abdominais, revisão de 447 autópsias. Arquivos de Medicina, 10 (1): 68-71.

(17) Magalhães T, Vieira DN (2008). A avaliação dos grandes traumatizados e a avaliação de terceira pessoa. In: Vieira DN e Quintero JA eds. Aspectos práticos da avaliação do dano corporal em Direito Civil. Caixa Seguros e Imprensa da Universidade de Coimbra. Coimbra. pp 59-69

(18) Magalhães T, Vieira DN (2010). Recomendações gerais para a realização de relatórios periciais de clínica forense no âmbito do Direito Civil. Revista Portuguesa do Dano Corporal, XIX (20): 79-90.

(19) MINISTÉRIO DA SAÚDE (2006). Notificação de acidentes do trabalho fatis, graves e com crianças e adolescentes. Série A (2). Acedido no dia 26 de março de $2011 \mathrm{em}$ bvs.saude.gov.br/bvs/../ protocolo.not.acidentes-trab.pdf.

(20) OIT (2010). Normas internacionais de trabalho-guia de formação sindical. Acedido no dia 10 de fevereiro de 2011 em training.itcilo.it/actrav/ils_pt/guia\&decl/guianitoit.pdf.

(21) Oliveira Sá (1992). Clínica Médico-Legal da reparação do dano Corporal em Direito Civil. APADAC, Coimbra.

(22) OMS (2010). Plano de Promoção da Educação,Segurança e Prevenção. Acedido no dia 13 de março de 2011 em zona.s.ptdefaut.asp.page $=3996$.

(23) Perez MG-B (2006). Nuevo Manual de Valoración y Baremación del Daño Corporal. $14^{\circ}$ ed. Granada: Editorial Comares.

(24) Ramirez LB (1996). Tiempos de Curación en Traumatologia. Madrid: Praxis 2.000.

(25) Rogier A: L'avis médical et l'expertise. Rev. Franç. Dommage Corp., 19(2):123-128.

(26) Tedeschi RG, Calhoun LG (1995). Trauma \& Transformation. Growing in the Aftermath of Suffering, Sage Publications, London. 
(27) Vieira DN (2000). A "missão" de avaliação do dano corporal em direito civil. Sub Júdice.pp.17:23-30.

(28) Vieira DN (2008). O Perito e a missão pericial em Direito Civil. In: Vieira DN e Quintero JA eds. Aspectos práticos da avaliação do dano corporal em Direito Civil. Caixa Seguros e Imprensa da Universidade de Coimbra. Coimbra. pp 35-59.

(29) Vieira DN, Corte-Real F (2008). Nexo de causalidade em Avaliação do Dano Corporal. In: Vieira DN e Quintero JA eds. Aspectos práticos da avaliação do dano corporal em Direito Civil. Caixa Seguros e Imprensa da Universidade de Coimbra. Coimbra. pp.61-83.

Resumo: Avaliação do dano corporal pós-traumático por acidentes de viação e de trabalho em Angola Em Angola não existe uma norma oficial para a avaliação médico-legal do dano corporal pós-traumático, pensada para cada âmbito do Direito em que a mesma tenha lugar. A entidade que superintende a avaliação deste dano, tendo em vista a sua indemnização, é a Comissão Nacional de Avaliação das Incapacidades Laborais, mas a maior parte dos exames periciais por acidentes de viação ou de trabalho são realizados pelas diversas empresas seguradoras. As perícias também podem ser efetuadas nos serviços do Departamento Nacional de Medicina Legal da Direção Nacional de Investigação Criminal de Angola, o qual se encontra, no entanto, direcionado para os exames periciais no âmbito do Direito Penal. Assim, o presente estudo tem como principal objetivo analisar e interpretar, do ponto de vista médico-legal e forense, as disposições orientadoras da avaliação do dano corporal em vítimas de acidentes de viação e de trabalho em Angola, bem como a situação atual dessas avaliações periciais, tendo em vista contribuir para a promoção de uma metodologia de avaliação que, adequando-se ao sistema legal vigente, permita servir de instrumento para melhor harmonizar a avaliação e reparação do dano corporal naquele país. Foi efetuado um estudo observacional, com componente analítico, que consistiu numa análise de 301 relatórios médicos, elaborados no ano de 2010, no serviço de saúde da Empresa Nacional de Seguros de Angola (ENSA), no âmbito da avaliação do dano corporal pós-traumático por acidentes de viação $(n=104)$ e de trabalho $(n=197)$. Verificou-se que os relatórios periciais: (1) não descrevem os antecedentes patológicos e traumáticos das vítimas; (2) descrevem o mecanismo do traumatismo/acidente, sem contudo o pormenorizar; (3) em 3\% dos casos não fazem referência às lesões resultantes nem à localização dessas lesões; (4) em $93 \%$ dos casos não descrevem as sequelas a nível do corpo; (5) em quase $100 \%$ não descrevem as sequelas funcionais nem situacionais; (6) nunca é feita referência ao nexo causalidade entre o traumatismo e o dano; (7) em $66 \%$ dos casos não fazem referência à data de consolidação médico-legal das lesões; (8) em $54 \%$ dos casos não fazem referência aos parâmetros de dano temporário; (9) em $99 \%$ dos casos não fazem referência aos parâmetros de dano permanente. Neste sentido, é necessária uma reflexão profunda sobre a problemática da valoração do dano corporal pós-traumático por acidentes de viação e de trabalho em Angola, necessitando de se definir e harmonizar uma metodologia, a qual será fundamental para garantir a equidade da avaliação e, consequentemente, a justiça da reparação.

Palavras-chave: Dano corporal; Acidente de viação; Acidente de Trabalho; Avaliação médico-legal; Direito Civil; Direito do Trabalho; Indemnização. 
Summary: Bodily harm assessment on traffic and work accidents victims' in Angola In Angola there isn't an official norm for forensic evaluation of post-traumatic bodily harm, indicated for each scope of the Law in which it takes place. The entity that supervises the evaluation of this harm, in order to enable its compensation sums, is the National Commission of Evaluation of Work Disabilities, but most examinations of traffic or work related accidents are made by the insurance companies. These examinations can also be made by the Department of Legal Medicine of the Angolan National Board of Criminal Investigation, which is mainly focused on examinations for Penal Law. Therefore, the aim of this study is to analyze and interpret, from the medico-legal and forensic point of view, the procedures of the evaluation of bodily harm on traffic or work victims in Angola, as well as the current situation of those evaluations, focusing on a contribution for the promotion of a methodology of evaluation that if suitable to the legal system, may serve as an instrument to improve the evaluation and restore of bodily harm in that country. An observation study was carried out, with an analytical component, that consisted in an analysis of 301 medical reports, elaborated in the year 2010, on the health department of the National Insurance Company of Angola, concerning the evaluation of post-traumatic bodily harm in traffic accidents ( $n=104)$ and work ( $n=197)$, and the corresponding compensation sums. Medical reports: (1) do not describe the pathological and traumatic background of the victim; (2) describe the trauma/accident but with no details; (3) in $3 \%$ of the cases do no refer to injuries that resulted from the accident nor to the location of those injuries; (5) in almost $100 \%$ do not describe functional nor situational sequels; (6) the causality between trauma and damage is never mentioned; (7) in $66 \%$ of the cases do not mention the date of the medico-legal consolidation of the injuries; (8) in $54 \%$ of the cases do not mention the temporary bodily harm parameters; (9) in $99 \%$ of the cases do not mention the permanent bodily harm parameters. Accordingly, a profound reflection is necessary about the problem concerning de value of post-traumatic bodily harm caused by traffic or work accidents in Angola, and it is necessary to outline and regulate a methodology, that will be fundamental to ensure the equity of the evaluation and, consequently, the justice of the compensation.

Key-words: Bodily harm; Traffic accident; Forensic evaluation; Civil law; Labour Law; Compensation.

Résumé: Évaluation des dommages corporels dus aux accidents de la route et du travail en Angola En Angola, il n'y a pas de norme officielle pour l'évaluation médico-légale du dommage corporel post- traumatique conçue pour chaque domaine du Droit où celle-ci serait insérée. L'institution qui surveille l'évaluation de ce dommage, ayant comme but le paiement de dommages et intérêts, est la "Comissão Nacional de Avaliação das Incapacidades Laborais» (Commission Nationale de l'Évaluation des Incapacités du Travail) mais la plupart des examens des experts pour cause d'accidents de la route ou de travail est réalisée par les plus diverses sociétés d'assurance. Les expertises peuvent aussi être effectuées dans les services du «Departamento Nacional de Medicina Legal da Direção Nacional de Investigação Criminal de Angola» (Département National de Médecine Légale de la Direction Nationale de la Recherche Criminelle de Angola), lequel est néanmoins tourné vers les examens/ 
expertises dans le domaine du Droit Pénal. Dans ce sens, la présente étude a comme principal objectif analyser et interpréter, du point de vue médico-légal et du barreau, les mesures pour l'orientation de l'évaluation du dommage corporel sur des victimes d'accidents de la route et de travail en Angola, ainsi que la situation actuelle de ces évaluations/ expertises, ayant comme but contribuer à la promotion d'une méthodologie d'évaluation qui, en s'adaptant au système légal en vigueur, permette de servir comme un instrument pour mieux harmoniser l'évaluation et la réparation du dommage corporel dans ce pays. Il a été effectué une étude observationnelle, comme composant analytique, qui a consisté en une analyse de 301 rapports médicaux, élaborés pendant l'année 2010, au service de santé de «Empresa Nacional de Seguros de Angola ENSA» (Société National d’Assurance de Angola), en ce qui concerne le dommage corporel post-traumatique par accidents de la route $(n=104)$ et par accidents de travail ( $n=197)$. On a vérifié que les rapports des expertises : (1) ne décrivent pas les antécédents pathologiques et traumatiques des victimes ; (2) décrivent le mécanisme du traumatisme/ accident, sans néanmoins donner des détails ; (3) en $3 \%$ des cas il n'y a de références ni aux lésions résultantes, ni à la localisation de ces lésions ; (4) en $93 \%$ des cas ils ne décrivent pas les séquelles au niveau du corps; (5) en presque $100 \%$ ils ne décrivent ni les séquelles fonctionnelles ni situationnelles ; (6) jamais il n'est fait référence à la connexion de causalité entre le traumatisme et le dommage ; (7) en $66 \%$ des cas il n'est pas fait référence à la date de consolidation médico-légale des lésions ; (8) en $54 \%$ des cas il n'est pas fait référence aux paramètres de dommage temporaire ; $(9)$ en $99 \%$ des cas il ne font pas référence aux paramètres de dommage permanent/ définitif. Dans ce sens, il faut une réflexion profonde sur la problématique de la majoration du dommage corporel post-traumatique causé par des accidents de la route et de travail en Angola, étant pour cela nécessaire de définir et d’harmoniser une méthodologie, laquelle sera fondamentale pour garantir l'équité de l'évaluation et, par conséquence, la justice de la réparation.

Mots-clés: Dommage corporel; Accident de la route; Accident de travail; Évaluation médico-légale; Droit Civil; Droit du Travail; Dommages et intérêts.

\section{Agradecimentos}

À ENSA (Empresa Nacional de Seguros de Angola), pelo acolhimento dado durante o trabalho de campo para recolha de dados. Ao Ministério do Interior e ao Comando Geral Polícia Nacional de Angola, pelo empenho na formação de quadros no ramo da Medicina Legal e outras Ciências Forenses em Angola.

\section{Pedido de Separatas:}

GUIDO SÓZINHO

guidosozinho@hotmail.com 